\title{
DOCUMENTACIÓN DE LA IGLESIA DE SANTO TOMÁS A PARTIR DE LA FOTOGRAMETRÍA Y LOS SISTEMAS
}

\author{
Documentation of the Church of Santo Tomás from photogrametry and systems
}

\author{
José Félix Pearce Pérez, Arq. \\ Universidad de Oriente, Cuba \\ https://orcid.org/0000-0002-9186-3615 \\ pearce@uo.edu.cu
}

Palabras claves: Documentación, Patrimonio, Fotogrametría, Fotografía Rectificada.

Keywords: Documentation, Heritage, Photogrammetry, Rectified Photography.
Recibido: 11 de octubre de 2018

Aceptado: 20 de febrero de 2019

\section{RESUMEN}

La utilización de las técnicas y herramientas digitales para la documentación del patrimonio cultural construido incide de manera positiva en los esfuerzos que realizan profesionales e investigadores de la temática. La fotografía digital convencional, fotografía rectificada, fotogrametría y los sistemas CAD, han devenido en herramientas imprescindibles para la documentación del patrimonio edificado. En la actualidad aún resultan escasas las experiencias en el uso de estas técnicas de avanzada para la documentación del patrimonio cultural construido. Esta situación se refleja en la documentación gráfica existente de la iglesia de Santo Tomás, considerada uno los templos más antiguos, valiosos y característicos de la arquitectura religiosa colonial en Santiago de Cuba. El presente trabajo tiene como objetivo: documentar a la iglesia de Santo Tomás a partir del uso de técnicas y herramientas digitales, que permitan mayor precisión y nivel de detalle en la información gráfica que se genere. Con el cumplimiento de los objetivos propuestos se logran aportes metodológicos y prácticos, que muestran el uso de técnicas y herramientas digitales específicamente la fotogrametría y los sistemas CAD para perfeccionar y ampliar la documentación gráfica de la iglesia de Santo Tomás con la finalidad de contribuir a las acciones de intervención en el inmueble.

\begin{abstract}
The use of digital tools and techniques for the documentation of the built cultural heritage has a positive impact on the efforts made by professionals and researchers on the subject. Conventional digital photography, rectified photography, photogrammetry and CAD systems have become essential tools for the documentation of built heritage. In the local context, there are still few experiences in the use of these advanced techniques for the documentation of the built cultural heritage. This situation is reflected in the existing graphic documentation of the Church of Santo Tomas, considered one of the oldest, most valuable and characteristic temples of colonial religious architecture in Santiago de Cuba. The objective of this paper is to document the church of Santo Tomas from the use of digital tools and techniques, which allow greater precision and level of detail in the graphic information generated. With the fulfillment of the proposed objectives, methodological and practical contributions are achieved, which show the use of digital tools and techniques specifically photogrammetry and CAD systems to improve and expand the graphic documentation of the Santo Tomas church with the purpose of contributing to the intervention actions in the property.It fosters the theory-practice link and gives a leading role to students in their learning process.
\end{abstract}




\section{INTRODUCCIÓN}

En la actualidad es importante conocer y adentrarse en el estudio de la documentación digital del patrimonio construido; para ello es preciso examinar las investigaciones que diferentes autores han desarrollado sobre el tema. En este caso resulta imprescindible abordar los ejemplos internacionales y nacionales que muestran las experiencias en el novedoso campo de la documentación del patrimonio a partir del uso de herramientas y técnicas digitales.

Esta búsqueda determinó los referentes metodológicos y prácticos que rigen la presente investigación para la documentación digital del templo Santo Tomás de Santiago de Cuba.

\section{DESARROLLO}

\section{El registro, documentación y gestión de la información como parte de la conservación del patrimonio construido}

Desde 1931, a través de la Carta de Atenas adoptada en el primer congreso internacional de arquitectos y técnicos de monumentos históricos, el registro, documentación y gestión de la información como parte de la conservación del patrimonio construido ha evolucionado paulatinamente. En la 11 na Asamblea General de ICOMOS, celebrada en Bulgaria en 1996 se definen los principios para el registro y documentación de monumentos, grupos de edificaciones y sitios, de esta manera se insistió en la importancia de este proceso para la conservación del patrimonio.

En 2007, el Instituto de Conservación Getty de Los Ángeles publicó dos volúmenes. En el primero Recording, Documentation and Information Management for the Conservation of Heritage Places. Guiding Principles (Letellier, 2007) se plantean preceptos metodológicos que pautan el proceso de documentación del patrimonio. Mientras, que el segundo Recording, Documentation and Information Management for the Conservation of Heritage Places. Illustratedexamples (Eppich, 2007) enfoca los análisis hacia la necesidad del uso de las herramientas y técnicas digitales modernas en orden de optimizar los esfuerzos en el campo de la conservación del patrimonio.

En la actualidad, las técnicas digitales han devenido como las principales herramientas que sustentan el trabajo de registro y documentación del patrimonio construido. Los avances tecnológicos han permitido desarrollar técnicas menos invasivas y de mayor precisión a la hora de realizar las tareas de levantamientos. El almacenamiento de la información es garantizado en sitios seguros y accesibles, permitiendo que los datos digitales puedan migrar a versiones actualizadas de software donde se puedan lograr mejores resultados del procesamiento de la misma. Organizaciones como el Comité Internacional para la Documentación del Patrimonio Cultural (CIPA) han fomentado el uso de las herramientas digitales aplicadas a la conservación de sitios patrimoniales.

Técnicas y herramientas digitales

Diversas herramientas y técnicas digitales son utilizadas para el registro y la documentación del patrimonio cultural edificado. En este sub-epígrafe se relacionan aquellas que serán utilizadas en el presente trabajo.

\section{- Fotografía convencional}

La fotografía convencional constituye el volumen de fotografías ordinarias llevadas a la conservación, es normalmente la fotografía tomada de manera oblicua al objeto y utilizada en cualquiera de la amplia gama de cámaras cotidianas, desde las de foco automático hasta las de modelos profesionales.

Aunque es una forma primaria de documentación, la fotografía convencional generalmente no es usada para propósito de estudio. No obstante, puede usarse para las mediciones utilizando algunos métodos. Cada conservación profesional, de vez en cuando, toma una fotografía que contiene un objeto fotografiado a escala que sirve para la calibración de algunas dimensiones. Éste método es muy útil, pero debe de realizarse con mucha precisión debido a que realizar una fotografía convencional a escala es muy difícil de lograr. Si al menos se dispone de dos fotografías de la misma escena, es posible realizar un segundo método con la fotografía convencional para lograr un correcto dimensionamiento. Técnicamente, este proceso necesita los servicios de un especialista en fotogrametría, y con la ayuda de algún programa digital disponible es posible extraer algunas dimensiones de las imágenes tomadas. Eppich, (2007)

\section{- Rectificación fotográfica}

Esta metodología permite documentar elementos planos u objetos que puedan descomponerse en diferentes planos, las precisiones son inferiores a las conseguidas por los otros métodos, pero el adjuntar la información fotográfica es 
tan importante que en algunos trabajos la hacen altamente rentable. La información aportada por la fotografía es importantísima en los trabajos de documentación y restauración, ya que facilita el conocimiento del objeto a restaurar, tipos de materiales, deterioros, humedades, pérdidas y el color. Aunque la rectificación sólo se puede emplear en elementos planos, podemos dotarla de información tridimensional. Lodeiro (2010).

La fotogrametría arquitectónica de objeto cercano a partir de imagen y de láser escáneres, es la herramienta de medición indirecta más extendida en las labores de cartografiado y de documentación patrimonial. Básicamente permite realizar el mapeado preciso de volumetrías y superficies a altas resoluciones. Se pueden clasificar los productos derivados del levantamiento fotogramétrico en tres niveles (pasando de lo tradicional a lo más avanzado):

Productos clásicos: planos a diversas escalas de planta y alzados; secciones horizontales y verticales; planos topográficos con curvas de nivel.

- Primeros productos digitales: rectificaciones de objetos planos y orto fotos (ortoimágenes) de superficies no planas, tanto a nivel de planta como de alzado. Las imágenes rectificadas u ortorectificadas servían de base de las representaciones vectoriales obtenidas en el primer nivel, proporcionando información adicional de texturay color.

- Productos actuales: nubes de puntos en 3D (a color o con niveles de intensidad), modelos digitales sin texturizar (y asignación de color o textura virtual) y modelos foto realísticos 3D fieles (asignando la textura verdadera proveniente de las imágenes fotográficas). Lerma, Cabrelles, Seguí, \& Navarro (2011).

- Sistema CAD

Autodesk AutoCAD es un programa de diseño asistido por computadora para dibujo en dos y tres dimensiones, este gestiona una base de datos de entidades geométricas (puntos, líneas, arcos, etc.), con la que se puede operar a través de una pantalla gráfica en la que se muestran éstas, el llamado editor de dibujo. Procesa imágenes de tipo vectorial, aunque admite incorporar archivos de tipo fotográfico o mapa de bits, donde se dibujan figuras básicas o primitivas (líneas, arcos, rectángulos, textos, etc.), y mediante herramientas de edición se crean gráficos más complejos. El programa permite organizar los objetos por medio de capas o estratos, ordenando el dibujo en partes independientes con diferente color y grafismo.

El dibujo de objetos seriados se gestiona mediante el uso de bloques, posibilitando la definición y modificación única de múltiples objetos repetidos. Parte del programa AutoCAD está orientado a la producción de planos, empleando para ello los recursos tradicionales de grafismo en el dibujo, como color, grosor de líneas y texturas tramadas. AutoCAD, a partir de la versión 11, utiliza el concepto de espacio modelo y espacio papel para separar las fases de diseño y dibujoen 2D y 3D, de las específicas para obtener planos trazados en papel a su correspondiente escala.

\section{Experiencias en la implementación de las técnicas digitales para el registro y documentación del patrimonio cultural edificado a nivel internacional}

El desarrollo de las técnicas digitales ha abierto nuevos horizontes en el campo del registro y documentación de inmuebles patrimoniales. El presente epígrafe aborda los ejemplos en el contexto internacional de las iglesias San José de Elche y Santa María (Requena) en las provincias de Alicante y Valencia, España, ambos inmuebles ostentan elevados valores arquitectónicos que fueron documentados a partir del uso de la fotogrametría, el escáner láser y los sistemas CAD.

\section{Iglesia de San José de Elche}

La aplicación de la fotogrametría como técnica de digitalización para el registro y documentación del patrimonio cultural edificado a nivel internacional ha sido de gran importancia. Ejemplo de esto se puede encontrar en el levantamiento gráfico de la iglesia de San José, localizada en Elche provincia de Alicante, España. (Fig. 1)

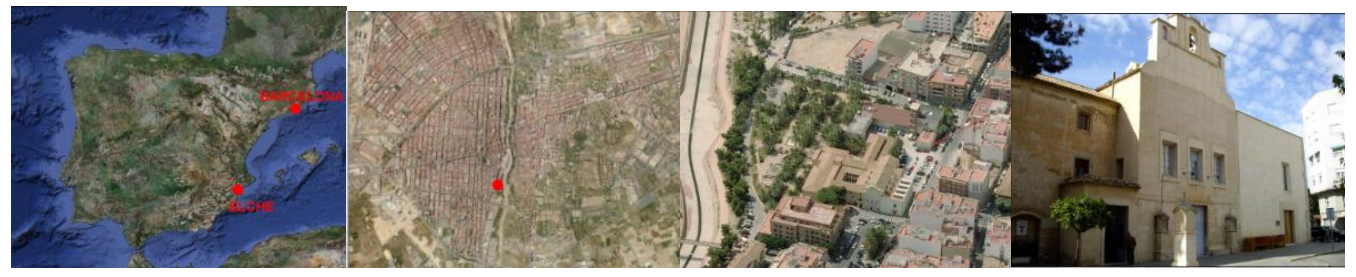

Fig. 1: De izquierda a derecha ubicación de la ciudad de Elche y emplazamiento de la iglesia San José.

Fuente: (Mora García, Céspedes López, \& Louis Cereceda, 2009) 
El inmueble tiene la categoría de Bien de Interés Cultural y está clasificado en el Plan Especial de Protección con un grado de protección integral. Mora García (2009.

Para el levantamiento gráfico se empleó un medidor y un nivel láser, estos instrumentos de medición fueron complementados con el uso de la estación total, utilizándose para definir las alturas en fachadas, huecos y posibles desplomes. Una fase importante del trabajo de campo radica en la correcta toma de fotografías, las cuales fueron realizadas con cámaras digitales de uso común, de este paso dependerá la calidad de los resultados de la restitución fotogramétrica.

El software Photomodeler Scanner fue utilizado para el procesamiento de las fotografías y construcción a partir de estas de la fotogrametría de la iglesia. El resultado obtenido fue la construcción de un modelo 3D a escala del inmueble. (Fig. 2)

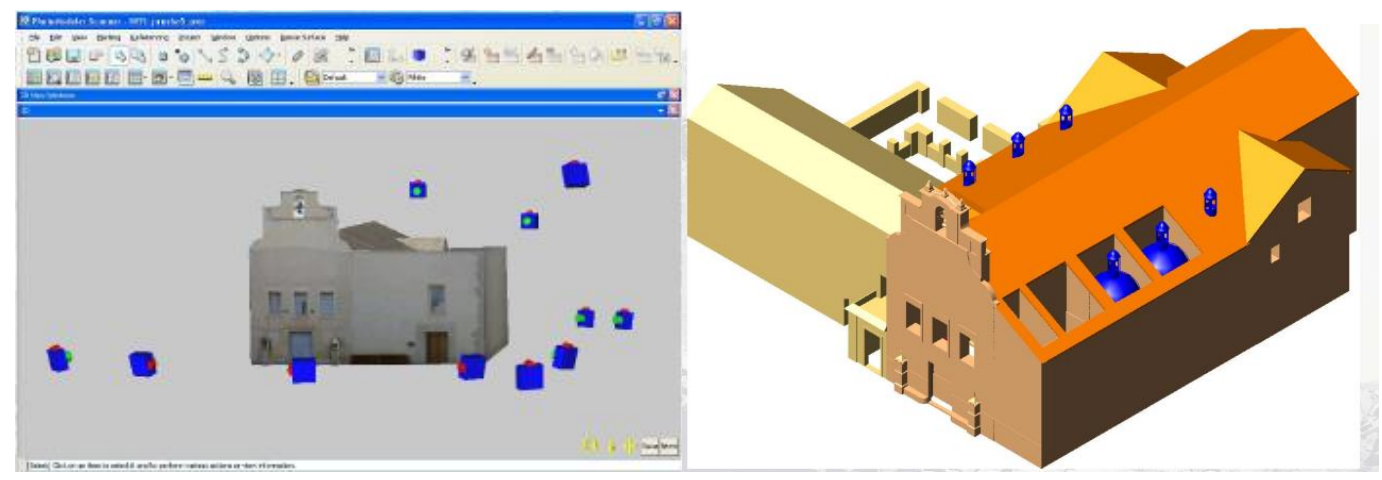

Fig. 2: Resultado del levantamiento de la iglesia de San José en Elche a partir del Photomodeler, donde se pone en práctica el uso la fotogrametría (izquierda). Modelo tridimensional (derecha).

Fuente: (Mora García et al., 2009)

Desde el modelo 3D se generaron dibujos CAD de planos arquitectónicos, ortofotos,vistas, fotomontajes y perspectivas del edificio. Las ortofotos, al ser proyeccionesortogonales, permiten medir directamente sobre ellas, además de servir de base pararepresentar planos arquitectónicos. (Fig. 3)

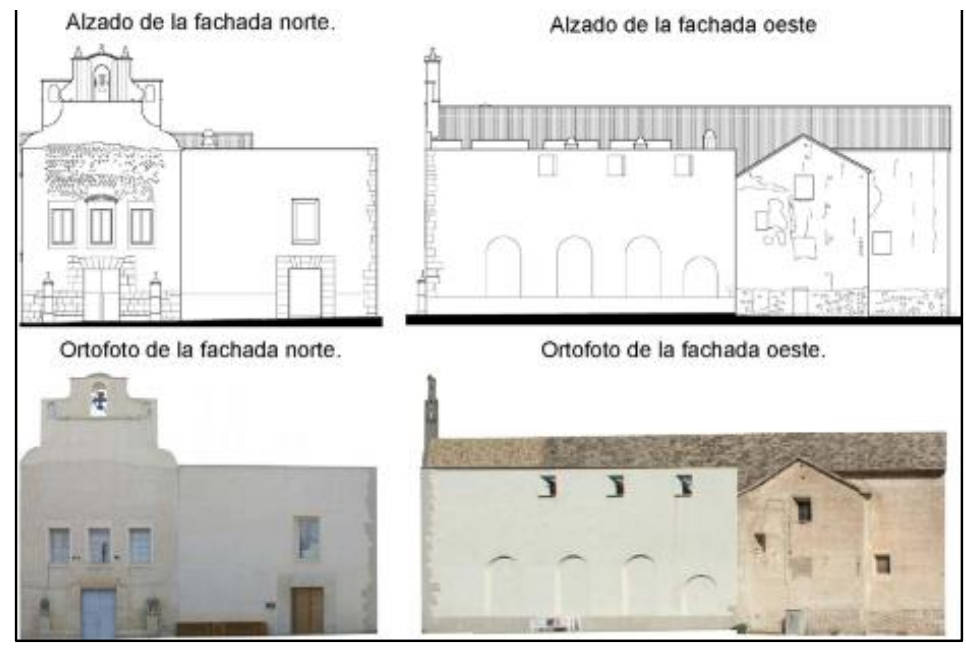

Fig. 3: Dibujo CAD de las vistas frontal y lateral realizado a partir de las ortofotos de la iglesia.

Fuente: (Mora García et al., 2009a)

La información aportada por las ortofotos es de gran utilidad, ya que reducen el tiempo de toma de datos en campo y permiten precisar con mayor exactitud las particularidadesde cada fachada o elemento a estudiar. Mora García (2009).

Del análisis de este ejemplo se puede destacar la utilización de la fotogrametría para el levantamiento del patrimonio edificado. En este sentido, se demuestra cómo resulta ser un sistema que propicia mucha información y al mismo tiempo constituye una herramienta de asequibles costes económicos. 
Experiencias en la implementación de las técnicas digitales para el registro y documentación del patrimonio cultural edificado en el contexto nacional

En el contexto cubano existen experiencias en el registro y documentación del patrimonio cultural edificado aplicando técnicas digitales. Este epígrafe aborda los ejemplos de los trabajos realizados en el Convento de Santa Teresa por la Oficina del Historiador de La Ciudad de La Habana y en el casco histórico de la ciudad de Holguín.

\section{Convento de Santa Teresa}

La Oficina del Historiador de La Habana realizó el levantamiento de la sección más compleja de la fachada del Convento Santa Teresa donde empleó la fotogrametría terrestre a partir de imágenes obtenidas con cámaras fotográficas digitales.

Para desarrollar los trabajos de campo; inicialmente, se hizo un reconocimiento del objeto de estudio, realizando las mediciones básicas y los croquis del levantamiento. En este caso, se utilizaron marcadores o puntos de control en la fachada del inmueble como apoyo para realizar posteriores mediciones auxiliadas de la estación total. Para la ubicación de estos puntos deben seleccionarse lugares 'foto-identificables' de forma que garanticen la precisión y exactitud requerida en la orientación y escalado. (Rodríguez, García, Piñero, \& Cruel, s. f.)

El levantamiento fotográfico se realizó garantizando que la dirección del eje de la cámara quede cercana a la perpendicular con respecto al plano principal del objeto a levantar, esto no constituye una condición obligatoria, pero facilita los trabajos fotogramétricos posteriores. (Fig. 4)
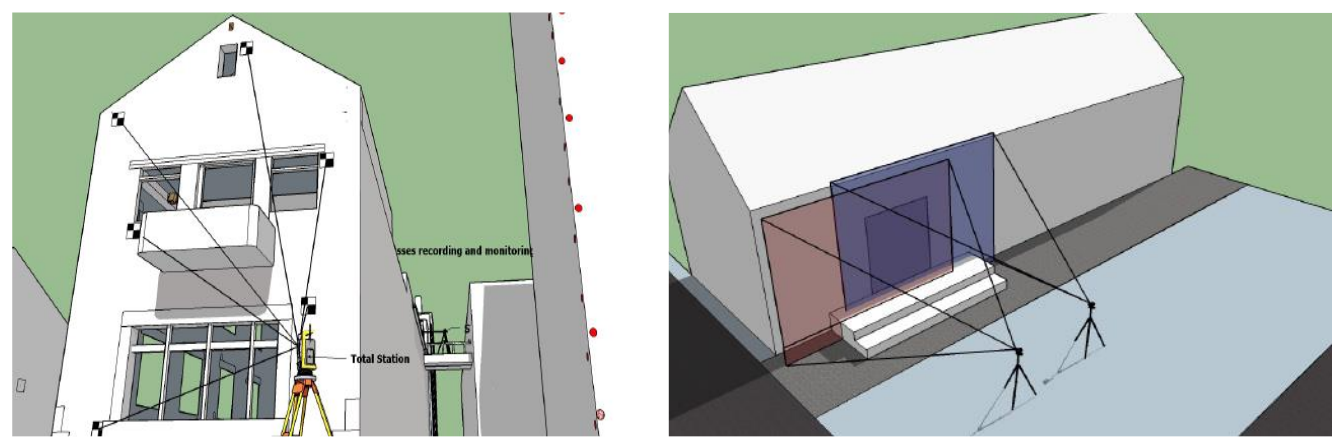

Fig. 4: Ejemplos de marcadores o puntos de control ubicados en una fachada (izquierda). Posición perpendicular de la cámara con respecto a la fachada (derecha).

Fuente: («Survey Guide», 2015)

Las coordenadas de los puntos de la fachada se determinaron con una estación total Leica. Las mismas sirvieron a su vez para el escalado del modelo 3D generado a partir de la fotogrametría del inmueble. (Fig. 5) La ortofoto escalada de la fachada del convento sirvió como base para el posterior dibujo vectorial. El mismo fue realizado utilizando el software AutoCAD donde se generaron los planos de las elevaciones de la fachada con las dimensiones detalladas de la misma. El margen de error percibido en el dimensionamiento de la fachada fue mínimo demostrando la gran precisión que se obtiene del trabajo conjunto a partir del uso fotogrametría y la estación total.

Con el análisis de este ejemplo se demostró la alta precisión de los levantamientos realizados con el empleo de las herramientas digitales. La fotogrametría y los sistemas CAD han devenido en técnicas inestimables para el proceso de registro y documentación del patrimonio cultural edificado.

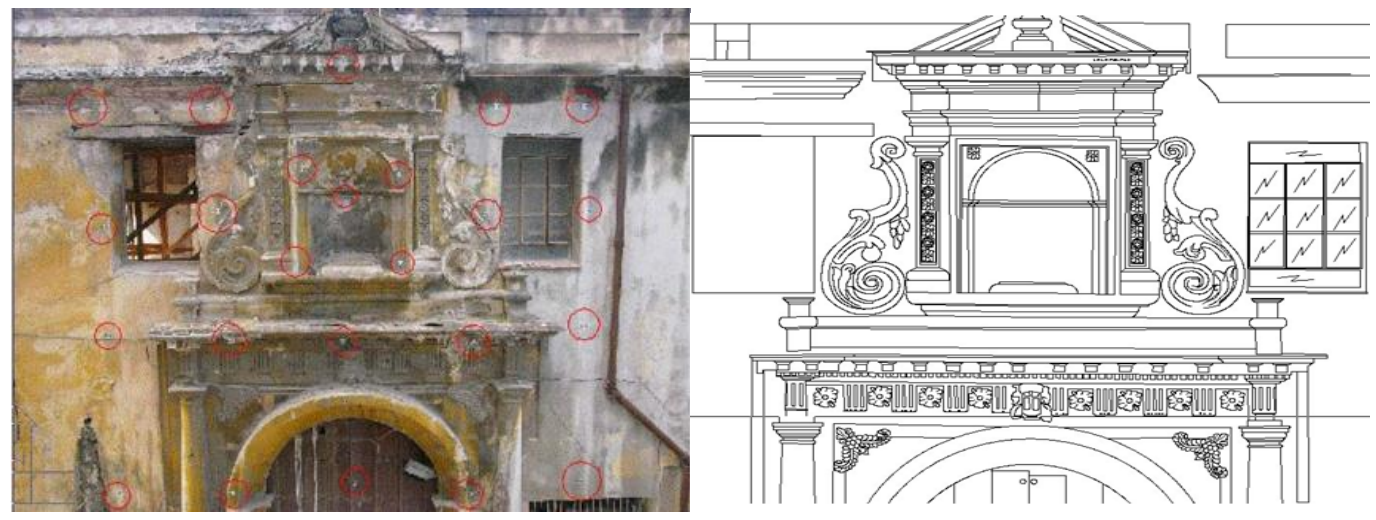


Fig. 5: Ortofoto de la fachada del Templo Santa Teresa donde se muestran los marcadores que se utilizaron para el escalado de la misma (izquierda). Dibujo vectorial de la fachada (derecha).

Fuente: (Rodríguez et al., s. f.)

\section{La iglesia de Santo Tomás}

La iglesia de Santo Tomás, exponente representativo del pre barroco, fue construida durante el transcurso del Siglo XVIII según ilustra una inscripción en su fachada, la cual indica más de 300 años de historia. El inmueble se ubica en las calles Santo Tomás y 30 de noviembre, aledaña a la Placita de Crombet, es del tipo de iglesia de tres naves y presenta una torre campanario a un costado de su fachada principal, al parecer de posterior construcción a la del templo. La misma ha sufrido transformaciones y modificaciones producto de derrumbes provocados por terremotos y por la inserción de nuevos espacios dentro de la misma.

En la actualidad existe un alto grado de deterioro en casi todo el inmueble, el cual no es visible en sus fachadas, pues a excepción de la falta de pintura, la caída del repello en varios lugares y algunos escalones deteriorados no presenta serios daños; mientras que, en su interior, se pueden observar claramente los serios problemas que le afectan. Esto se evidencia en las grandes grietas que presentan algunos de sus muros de cargas; en el alto grado de deterioro de los elementos decorativos de madera y yeso, entre los que encontramos alteres, pinturas, capiteles entre otros; en el mal estado de la cubierta que contribuye considerablemente a su deterioro, pues no guarece completamente el interior del mismo de los agentes atmosféricos.

En base a lo anterior el grupo de proyecto del arzobispado planteó la necesidad determinar, concretar y ampliar lo que faltaba en cuanto a término de documentación de los templos coloniales en el centro histórico. Todo esto como punto de partida para una posterior intervención de restauración en los templos coloniales, específicamente la iglesia de Santo Tomás.

En base a estas razones, se plantea en este artículo el empleo de técnicas y herramientas digitales que permiten complementar, perfeccionar y ampliar la documentación gráfica de la iglesia Santo Tomás por cuanto se plantea por parte del grupo de proyecto del arzobispado la necesidad de contar con información detallada sobre el inmueble que contribuya a las acciones posteriores de intervención. Se presenta un procedimiento metodológico diseñado para realizar la documentación gráfica de dicha iglesia, a partir de la utilización de técnicas y herramientas digitales como la fotografíaconvencional, la fotogrametría, la fotografía rectificada y los sistemas CAD.

\section{Procedimiento metodológico para la documentación digital de la Iglesia de Santo Tomás}

\section{- Descripción del inmueble}

La descripción e identificación de los objetos de estudios fue realizada a partir de los estudios previos recogidos en el informe técnico "Iglesia Santo Tomás" del grupo de arquitectos e ingenieros del Arzobispado de Santiago de Cuba. (Grupo de arquitectos e ingenieros, s. f.)

\section{- Planimetría}

El inmueble se desarrolla en una planta rectangular estructurada en tres naves, responde al esquema de una nave principal y dos laterales. Presenta una superficie total de $624 \mathrm{~m} 2$ y un área construida de $530 \mathrm{~m} 2$ incluidas la torre campanario con $15.60 \mathrm{~m} 2$ y la capilla del Santísimo de $23.75 \mathrm{~m} 2$.

El acceso principal al templo se realiza a través del atrio luego de salvar un desnivel respecto a la calle, cuenta con una superficie aproximada de $94 \mathrm{~m} 2$. El acceso secundario está ubicado en la fachada lateral sur.

\section{Exterior de la iglesia de Santo Tomás}

\section{Fachada principal (este)}




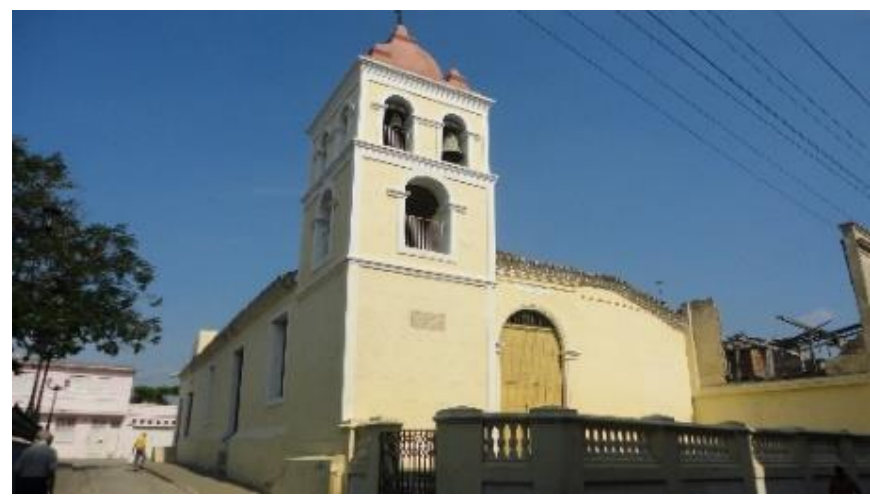

Fig. 6: De izquierda a derecha perspectiva del Templo tomada desde la calle Santo Tomás y acceso principal con puerta española de clavos respectivamente.

Fuente: autor

Su fachada principal es asimétrica al presentar la torre campanario en el extremo izquierdo, la cual está compuesta por tres cuerpos decrecientes en altura, los dos últimos poseen vanos coronados por arcos de medio punto y está rematada con una cúpula semiesférica rodeada por cuatro almenas en las esquinas del tercer cuerpo y una coronando la cúpula.

La única carpintería que posee corresponde con el acceso principal, cuya puerta es de tipo española de clavos, rematada en su parte superior por un arco protegido por una herrería y enmarcado en un paño resaltado del muro con guarnición de orden toscano, formado por pilastras, basas y capiteles. (Fig. 6)

- Fachada lateral (sur)

Al igual que la fachada principal, la fachada lateral (sur) está rematada por alero de tejaroces de tres hiladas. Destaca el volumen cúbico que contiene en su interior a la cúpula principal del templo, la cual queda oculta desde el exterior. La cubierta del mismo está compuesta por tejas criollas a cuatro aguas. El acceso secundario al templo está compuesto por una puerta española de clavos y batientes de ventilación en la parte superior protegidos por herrería forjada. Las ventanas al interior del templo y a la casa parroquial son batientes de carpintería de madera, resguardadas con rejas de hierro forjado. En la parte izquierda de la fachada se localiza otra puerta que permite la entrada a la casa parroquial.

- Interior de la iglesia de Santo Tomás

Las tres naves que componen el templo se encuentran separadas por pies derechos guarnecidos con arquería de madera y simulando arcos de medio punto. Estos presentan capiteles y pedestales definidos a base de molduras escalonadas. La cubierta de la nave central es de alfarje de tres faldones rematado por un estrecho harneruelo, los faldones descansan sobre soleras de estribado. Posee cinco pares de tirantes y dos cuadrales esquineros formando la trabazón. Cada par de alfardas está ligado al harneruelo por tres ligaduras y en sus perímetros se adosan lacerías dibujando estrellas de doce puntas.

- Presbiterio

El presbiterio forma un espacio cuadrado del ancho de la nave central construido con muros de mampostería, así como los dos recintos menores a sus lados que funcionan como sacristías. Se encuentra separado de la nave central por un gran arco de medio punto el cual se repite adosado al muro del fondo. Otros dos arcos de menores tamaños, enlazan el presbiterio con las naves laterales.

Como techo, dispone de una cúpula de madera de dieciséis lados que nace de una pequeña cornisa sustentada por pechinas. Sobre la cúpula está el primitivo alfarje.

- Capilla del Sagrario

Ubicada en la nave lateral derecha. Está construida con muros de mampostería y dispone de una cúpula de madera de dieciséis lados sobre cornisas sustentadas por pechinas. Se accede a esta local por un arco de medio punto practicado en el muro.

- Identificación de los elementos a documentar 
A partir de los análisis antes realizados en el presente epígrafe se detallan los elementos que por sus características y valores arquitectónicos fueron documentados. Para ello se relacionan por tipo de elemento y sus características, se incorpora además una imagen de cada elemento (Tabla 1). Levantamiento de datos in situ

\section{- Trabajo de campo}

Para el levantamiento de los elementos documentados se utilizó la cinta métrica (Fig. 8) como herramienta para la toma de dimensiones, estos datos fueron incorporados en un croquis (Fig. 9) de cada elemento. Para el levantamiento fotográfico se utilizó una cámara semi-profesional modelo Canon EOS 1200D, la cual se empleó de forma diferenciada en dependencia de la ubicación del elemento a documentar; igualmente, fue necesario un trípode para evitar trepidaciones en la captura de imágenes (Fig. 10).
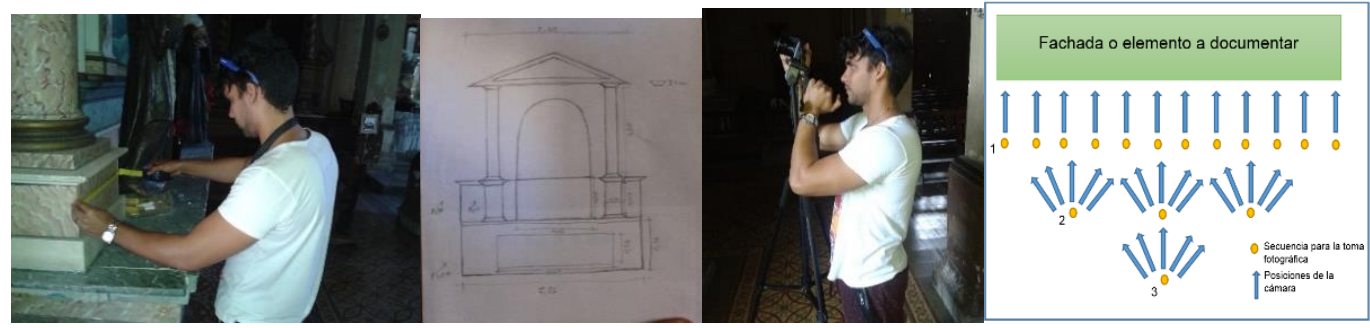

Fig. 8: Uso de la cinta métrica como herramienta para la toma de medidas.

Fig. 9: Empleo del croquis para la toma de datos in situ.

Fig. 10: Utilización de la cámara Canon EOS 1200D y el trípode para el levantamiento fotográfico.

Fig. 11: Se muestra la correcta secuencia y posición de la cámara para la toma fotográfica.

En el exterior del templo la cámara se ajustó de forma automática, debido a las óptimas condiciones de iluminación existentes. Las fotografías se realizaron desde distintas posiciones en un orden lógico. (Fig. 11)

En el interior de la iglesia la cámara se ajustó de forma manual, donde se eliminó el flash para obtener una correcta fotografía. En lugares muy oscuros, con escaza luz natural o artificial las fotografías fueron tomadas con diferentes niveles de exposición, al variar parámetros como el ISO, la apertura del lente y la velocidad de obturación.

\begin{tabular}{|l|l|}
\multicolumn{1}{|c|}{ PARTICULARIDADES DEL USO DE LA CAMARA EN } \\
DEPENDENCIA DEL LUGAR
\end{tabular}

Se tomaron un total de 949 fotografías las cuales fueron clasificadas de acuerdo al elemento documentado. Esto produjo un conjunto de carpetas y subcarpetas que contienen las fotos de los altares, el campanario, la carpintería, las columnas, las fachadas, los pisos y el techo.

Una vez realizada la recopilación de los datos se procedió a su procesamiento con el uso de técnicas y herramientas digitales.

\subsection{Procesamiento de datos}

El procesamiento de los datos se realizó una vez concluido el levantamiento fotográfico del Templo. El flujo de trabajo en el software Agisoft PhotoScan partió de alinear las fotografías de cada elemento para luego construir la nube de puntos, generar la malla irregular de polígonos (TIN) por sus siglas en inglés y finalmente el texturizado del modelo 3D respectivamente. La reconstrucción 3D de los elementos documentados se explicará en las siguientes etapas:

\section{Añadir las fotos}

Para añadir las fotos es necesario ubicar las mismas de cada elemento que se documentará de forma independiente. (Fig. 12) 


\section{Alinear fotos}

El programa Agisoft PhotoScan busca los puntos comunes en las fotos y las corresponde, así como también encuentra la posición de la cámara para cada cuadro y afina parámetros de calibración de la cámara. Como resultado se obtiene la nube escasa de puntos y se forma un set de posiciones de la cámara. (Fig. 13)

\section{Crear nube densa de puntos}

Basado en las posiciones estimadas de la cámara y cuadros se genera una nube densa de puntos, la cual puede ser editada y clasificada antes de exportar o generar de modelo de la malla de la modelación 3D. (Fig. 14)

\section{Crear malla}

Agisoft PhotoScan reconstruye una malla 3D poligonal que representa la superficie del objeto basada en la nube densa o escasa de puntos según la elección del usuario. (Fig. 15)

Después de que la geometría (o sea la malla) sea reconstruida, puede estar texturizada y usada para la generación del ortomosaico.

\section{Crear textura}

El modo de mapeado de la textura determina cómo estará la textura del objeto compacto en el atlas de la textura. La selección correcta de modo de mapeado de la textura ayuda a obtener textura óptima compactándose y, consecuentemente; la mejor calidad visual del modelo final. (Fig. 16)

\section{Crear ortomosaico}

A partir del texturizado del modelo obtenido se crea el ortomosaico, este sirve normalmente para la generación de imágenes de alta resolución basada en el modelo reconstruido. Este puede ser útil cuando una vista detallada del objeto es requerida.

\section{Exportar ortomosaico}

Al exportar el ortomosaico se obtiene la proyección ortogonal del elemento a partir del cual se puede medir directamente sobre él, además sirve como base para representar planos arquitectónicos. (Fig. 17)

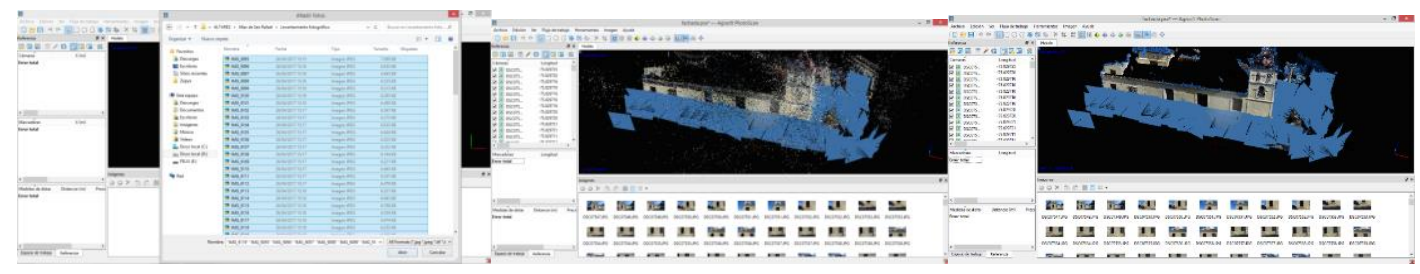

Fig. 12: Procedimiento para añadir las fotografías

Fig. 13: Procedimiento para alinear las fotos

Fig. 14: Procedimiento para crear la nube densa de puntos

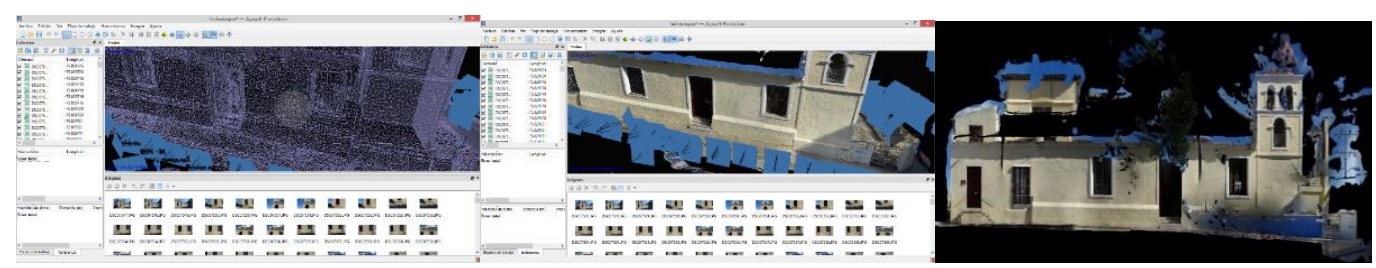

Fig. 15: Procedimiento para crear malla

Fig. 16: Resultado final a partir del texturizado del modelo

Fig. 17: Ortofoto generada a partir del modelo obtenido

Para poder generar y escalar las ortofotos obtenidas a partir de exportar el ortomosaico es necesario conocer al menos una dimensión del elemento a documentar, y a partir de ello emplear al menos 3 marcadores donde se señale que desde el marcador 1 al 2 la distancia es horizontal y que desde el marcador 1 al 3 la distancia es vertical. (Fig. 18) 


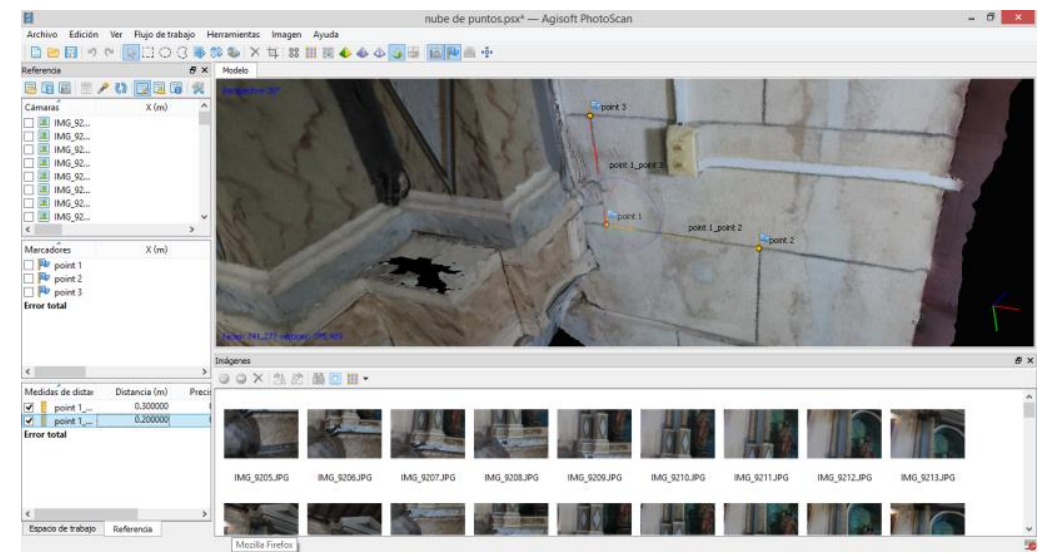

Fig. 18: Empleo de los marcadores para generar las ortofotos escaladas

\section{Fotografía rectificada}

El programa Perspective Rectifier se utilizó para la rectificación fotográfica del piso, ventanas, puertas y rejas en el interior de la iglesia. A partir de este programa se obtuvo la proyección ortogonal de los elementos documentados lo que propició dibujar de una manera más factible en el programa AutoCAD. En el caso del piso después de ser reproducido cada motivo se exportó al programa CoreIDRAW para ensamblarlos en la planta arquitectónica del templo. El piso, además de presentar una gama diversa de colores en su interior, posee una decoración muy variada.

Para el empleo de este programa es necesario ubicar 2 líneas horizontales y 2 verticales en el elemento a documentar que tengan la mayor precisión posible, esto permitirá una mejor proyección ortogonal de la imagen. La cual se exportará al programa AutoCAD para ser graficada. (Fig. 19)

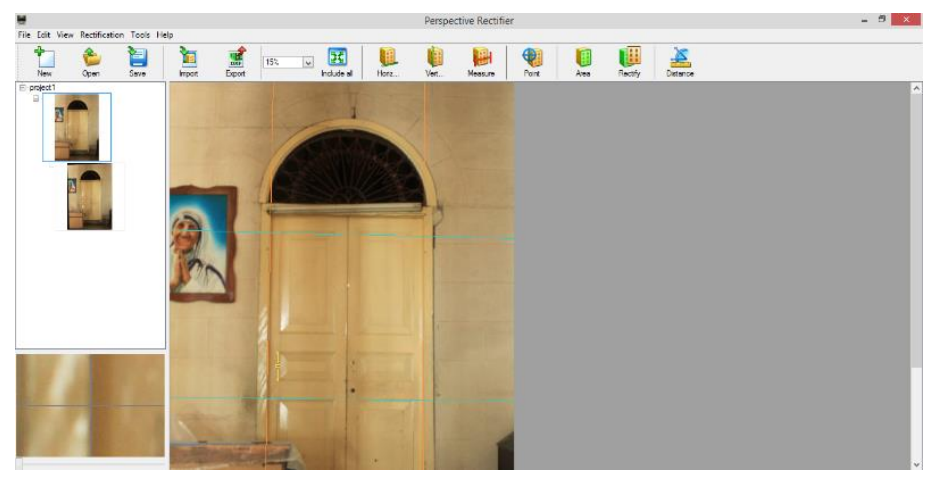

Fig. 19: Funcionamiento del programa Perspective Rectifier

\section{Implementación del sistema CAD para la documentación digital de la Iglesia de Santo Tomás}

El programa AutoCAD permitió elaborar el modelo bidimensional a partir de las ortofotos generadas en al programa Agisoft PhotoScan. El sistema CAD además de poder dibujar en las ortofotos generadas en el programa Agisoft PhotoScan permitió escalar algunos de los elementos. Para ello fue necesario conocer al menos una dimensión del objeto, esta se plasmó en una línea recta, la cual sirvió de referencia para escalar todo el dibujo.

\section{Resultados}

La planta arquitectónica de la iglesia de Santo Tomás que se muestra en el presente trabajo fue adquirida de los archivos del Grupo de Proyectos del Arzobispado. La misma fue construida a partir de la nube de puntos generada de la aplicación de un Escáner Láser. El resultado demuestra la alta precisión en los detalles de los ángulos y las dimensiones del inmueble. Esto se puede verificar al comparar esta versión de la planta con otras realizadas a partir del uso de técnicas más convencionales como los levantamientos utilizando cinta métrica. (Fig. 20)

La evidente ortogonalidad de los muros dibujados en las versiones anteriores es corregida con ayuda de los sensores láser. Del estudio detallado del dimensionamiento y, a partir de la posición real, entiéndase coordenadas de cada elemento, se puede visualizar el correcto espesor de muros y columnas del inmueble. El producto final resultó una información de partida indispensable para los posteriores trabajos realizados en el Templo. 


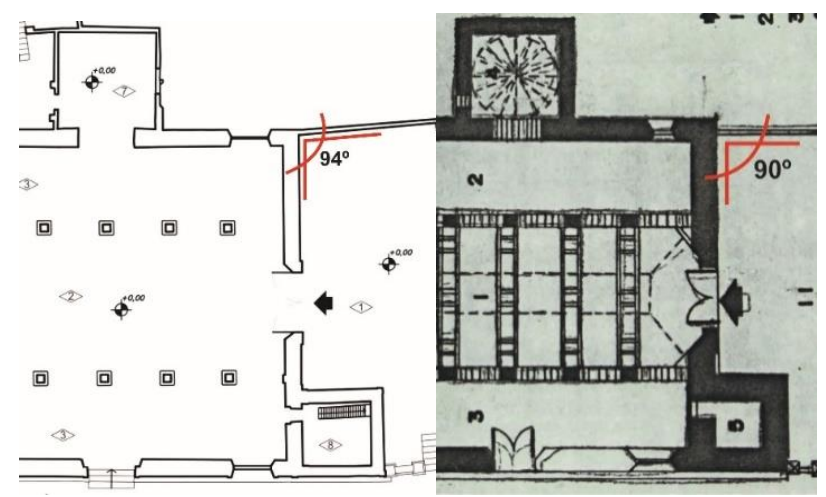

Fig. 20: Planta generada a partir del uso de Escáner láser (izquierda). Fuente: Archivo del Grupo de Proyecto del Arzobispado. Planta de forma ortogonal concebida a partir del uso de las técnicas tradicionales (derecha).

Fuente: (Noemi Barzana Rodriguez, Flora Morcate Labrada, Milene Soto Suarez, Monica Cabrera Ferriols, \& Omar Lopez Rodriguez, 1989)

A partir de la nube de puntos generada por el software Agisoft PhotoScan se obtuvo la volumetría real de las fachadas, accesos, altares, columnas y cubierta (Fig. 21). Cada volumetría expone las singularidades de los elementos permitiendo analizar en el resultado detalles e información de las texturas, materiales, colores, escala y nivel de deterioro que presenta en la actualidad la Iglesia.

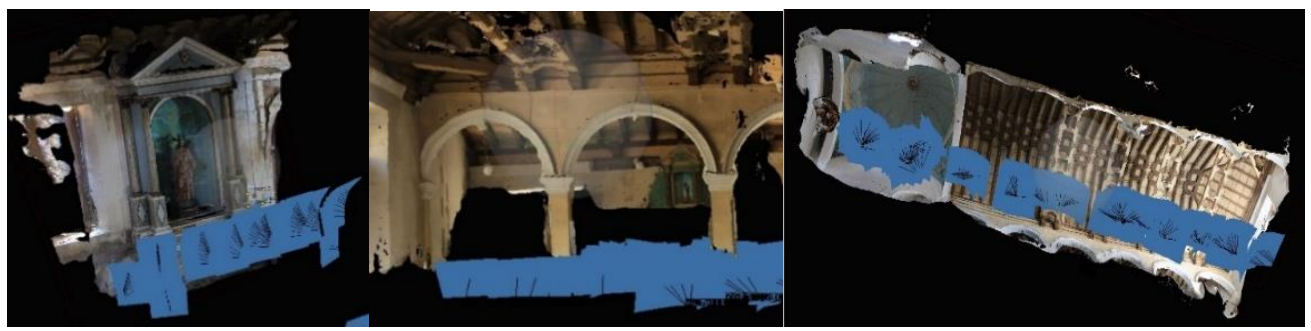

Fig. 21: Tridimensionalidad real del objeto

El estudio gráfico de las fachadas, elementos exteriores e interiores, altares y cubierta generados con sistema CAD demuestran en nivel de detalle las dimensiones, partes componentes y lesiones del templo. En la fachada principal puede observarse el desplazamiento y los ángulos de inclinación de las tejas criollas características que podemos afirmar es el resultado de los fuertes vientos producidos por huracanes. El levantamiento realizado a los altares del templo no cuenta con precedentes. El estudio, y modelación de los mismos fue en respuesta de la necesidad específica de contar con una documentación capaz de registrar cada detalle de los mismos. Los resultados exhiben las singularidades estilísticas de los siete altares, además se recoge la información referente a cada una de las esculturas e imágenes de los santos que componen cada uno. (Fig. 22)

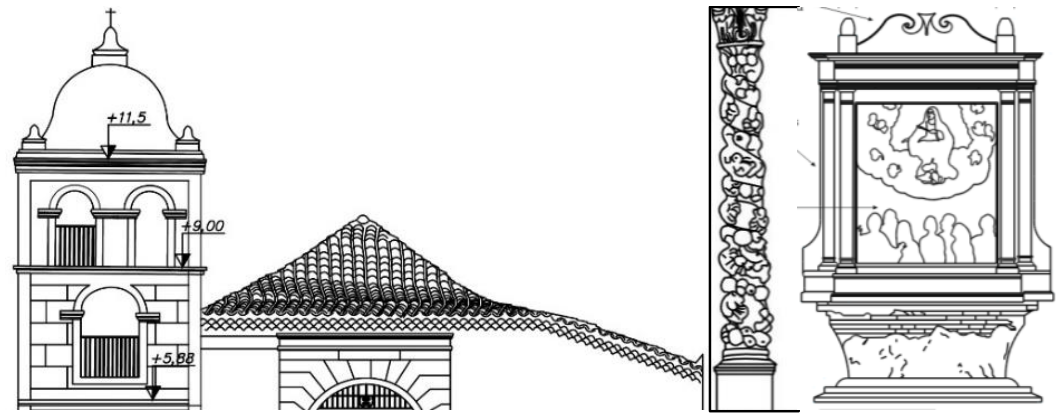

Fig. 22: La fachada principal muestra el ángulo de inclinación de la cubierta (izquierda). Detalle de las columnas del altar de San Rafael (centro). Altar de Almas del Purgatorio y lesiones (derecha) 


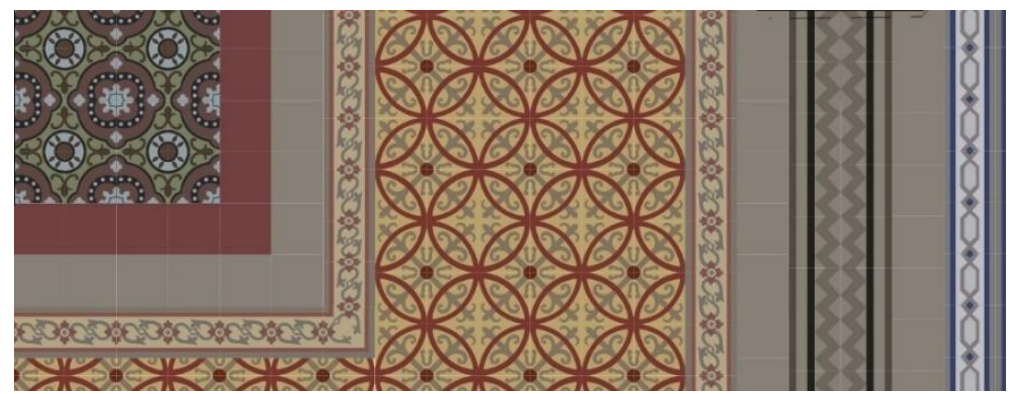

Fig. 23: Diversidad de diseño de los pisos (arriba). Paleta de color obtenida a partir del estudio los pisos (abajo)

\section{CONCLUSIÓN}

Se cumplió con el objetivo principal propuesto para ello fue necesario diseñar un procedimiento metodológico que parte de la identificación de los elementos a ser documentados, luego, en base a ello y los recursos disponibles se trazó la estrategia para el levantamiento y procesamiento de datos recopilados en la iglesia de Santo Tomás.

Los resultados alcanzados demuestran la necesidad de potenciar el uso de herramientas y técnicas digitales para la documentación de bienes patrimoniales. El uso de la fotografía convencional, la fotogrametría, la fotografía rectificada y los sistemas CAD como técnicas para la confección de la documentación gráfica de la iglesia de Santo Tomás han confirmado la precisión resultante del registro de la información de los elementos que definen este inmueble como un célebre exponente de la arquitectura religiosa de Santiago de Cuba.

\section{BIBLIOGRAFÍA}

1. Cayón, M. T., \& Veleta, F. (s. f.). Diccionario de la arquitectura colonial santiaguera. Universidad de Oriente, Santiago de Cuba.

2. Eppich, R. (2007). Recording, Documentation, and Information Management for the Conservation of Heritage Places.

3. Grupo de arquitectos e ingenieros. (s. f.). Iglesia Santo Tomás. Santiago de Cuba: Arzobispado de Santiago de Cuba.

4. Lerma, J. L., Cabrelles, M., Seguí, A. E., \& Navarro, S. (2011, febrero). La información geográfica y la gestión del patrimonio: Aplicación de la fotogrametría terrestre al levantamiento de alzados de edificios singulares.

5. Letellier, R. (2007). Recording, Documentation, and Information Management for the Conservation of Heritage Places. Guiding Principles. Los Angeles, USA: The Getty Conservation Institute. Recuperado a partir de https://www.getty.edu/conservation/publications_resources/pdf_publications/pdf/guiding_principles.pdf

6. Lodeiro, J. M. (2010). Documentación gráfica del Patrimonio.

7. Luis E. Bello Caballero, María T. Muñoz Castillo, \& Milene Soto Suárez. (2017). La información patrimonial en Santiago de Cuba. Proyecciones desde la Universidad de Oriente.

8. Mora García, Céspedes López, \& Louis Cereceda. (2009). Aplicación de la fotogrametría en el levantamiento gráfico de la iglesia de San José en Elche.

9. Barzana R, N, Morcate L, Soto S, Cabrera F, \& López R (1989). Atlas de la arquitectura religiosa en Santiago de Cuba del período colonial. Santiago de Cuba.

10. Quesada, A. L. R., Tamayo, R. N., Ayón, V. Á., Concepción, A. M. R., Hernández, F. M., Hernández, B. D, Betancourt, A. J. (2012). Aplicación de la fotogrametría arquitectural digital en la conservación de inmuebles patrimoniales (Vol. 11).

11. Quintero, M. S. (2013). Antecedentes, rol y desafío de la digitalización del patrimonio arquitectónico.

12. Rodríguez, B. D. D., García, S. H. G., Piñero, Y. B., \& Cruel, J. M. C. (s. f.). Levantamiento fotogramétrico de fachadas empleando cámaras no métricas. 